\title{
Penerapan Keselamatan Dan Kesehatan Kerja (K3) Di Daya Tarik Wisata Bounce Bali Desa Canggu Kecamatan Kuta Utara Kabupaten Badung
}

\section{Abel Kurniawan ${ }^{\text {a, }}$, Made Sukana ${ }^{\text {a, } 2}$}

1abelkurniawann@gmail.com,2madesukana@unud.ac.id

a Program Studi Sarjana Destinasi Pariwisata, Fakultas Pariwisata,Universitas Udayana, Jl. Dr. R. Goris No 7, Denpasar, Bali 80232 Indonesia

\section{Abstract}

Bounce Bali is one of the tourist attraction in Bali. It is located in Canggu Village, Kuta Utara District, Badung Regency. It offers an indoor trampoline activity. This sport has a potential risk. Therefore, it is essential to implement safety and healthy procedure.

The types of data are qualitative. This research analyzes the primary and secondary source of data. Data are collected through an observation, interview, and literature review. They are discussed descriptively. Qualitative data analyzes are carried out to understand the aim of the research.

The result of the study shows that Bounce Bali has been applied the safety and heathy procedure. They implement the standards of using the trampoline and provide the first aid facility.

Keywords: Trampoline Tourist Attraction, Safety and Healthy Procedure, Bounce Bali

\section{Pendahuluan}

Pariwisata di Bali terkenal dengan ciri khas budayanya yang unik yang tidak ada di daerah lain, selain itu Bali juga memiliki banyak daya tarik wisata alam dan buatan yang sudah terkenal di Indonesia. Salah satu daya tarik wisata buatan yang terkenal di Bali adalah Bounce Bali. Bounce Bali merupakan atraksi wisata buatan yang menawarkan wisata bermain Trampoline kepada pengunjung. Bounce Bali memiliki keunggulan, dimana merupakan wahana trampoline pertama dan terbesar di Bali . Bounce Bali berada di lokasi strategis atau daerah yang memiliki tingkat kunjungan wisatawan yang tinggi. Bounce Bali berlokasi di Canggu, Kabupaten Badung. Kaitannya dengan pariwisata Bounce Bali termasuk dalam sport tourism yang menyediakan atraksi wisata trampoline yang dapat dinikmati oleh semua jenis kalangan. Pengunjung dapat merasakan langsung sensasi melompat diatas matras yang berbahan karet, sehingga dapat memantulkan tubuh ke arah yang berlawanan.

Penggunaan atraksi wisata Trampoline yang ada di Bounce Bali tentu memiliki resiko kecelakan kepada pengunjung. Bounce Bali yang merupakan salah satu atraksi wisata buatan terbesar tentunya memiliki karyawan untuk menjalankan usahanya, setiap pekerjaan tentu akan memiliki berbagai resiko yang akan menyebabkan kecelakaan kerja, oleh karena itu hal tersebut maka Bounce Bali harus mampu menawarkan keamanan kepada para pengunjung. Demi pencapaian keamanannya, Bounce Bali harus bisa mengimplementasikan Kesehatan dan Keselaman Kerja bagi para karyawan dan wisatawan.

Setiap komponen penerapan Keselamatan dan Kesehatan Kerja (K3) menjadi bagian dari strategi perusahaan dalam mengembangkan sumber daya manusia sehingga mampu menimbulkan rasa aman bagi para pengunjung. Sebagai wahana wisata trampoline pertama di Bali, maka k3 harus diterapkan sehingga adanya jaminan keselamatan bagi para karyawan dan wisatawan.

Hal yang berkaitan perkembangan pariwisata yang berkaitan dengan atraksi wisata buatan terutama sport tourism diharapkan kedepannya dapat memberikan pemahaman mengenai penerapan Keselamatan dan Kesehatan Kerja (K3) pada pengunjung dan karyawan.

\section{Tinjauan Pustaka}

\subsection{Telaah Penelitian Sebelumnya}

Penelitian ini dirujuk dari penelitian yang dilakukan oleh Simon tahun 2016. Peneliti menguraikan tentang faktor yang dijadikan acuan penerapan Keselamatan dan Kesehatan Kerja menjadi dua faktor yaitu faktor internal: usia, penyakit khusus, peralatan keselamatan dan peraturan tertulis maupun tidak tertulis. Faktor eksternal membahas mengenai kondisi lingkungan sekitar Kawasan daya tarik wisata. Kesemaan penelitian terletak pada fokus penelitian yang sama-sama membahas Keselamatan dan Kesehatan Kerja. 
Rujukan kedua adalah penelitian yang dilakukan oleh Wiguna tahun 2016. Peneliti menjelaskan penerapan keselamatan dan kesehatan kerja pada pengunjung pantai Kuta berupa penyediaan layanan lifeguard. Penerapan keselamatan kesehatan kerja juga di tinjau dari para pekerja seperti lifeguard, yang di tinjau beberapa faktor internal yaitu kondisi psikologis, dan fisik yang memenuhi kriteria dan faktor eksternal seperti kondisi lingkungan. Kesamaan dari penelitian ini dilihat dari fokus penelitian yang membahas penerapan keselamatan dan kesehatan kerja yang di terapkan kepada karyawan.

\subsection{Tinjauan Konsep}

\subsubsection{Penerapan Keselamatan dan Kesehatan Kerja (K3)}

Keselamatan mencakup kedua istilah resiko keselamatan dan kesehatan. Keselamatan kerja menunjukan kondisi yang aman atau selamat dari penderitaan, kerusakan atau kerugian di tempat kerja. Resiko keselamatan merupakan aspek-aspek dari lingkungan kerja yang dapat menyebabkan kebakaran, ketakutan aliran listrik, terpotongm luka memar, keseleo, patah tulang kerugian alat tubuh penglihatan dan pendengaran (Mangkunegara 2001).

Implementasi adalah pelaksanaan keputusan kebijakan dasa,biasanya dalam bentuk undang-undang, namun dapat pula berbentuk perintah-perintah atau keputusankeputusan eksekutif yang penting atau keputusan badan peradilan. Semua program K3 ini harus dikontrol implementasinya secara periodik, baik secara intern maupun ekstern (Sugeng 2005).

\subsubsection{Tinjauan Atraksi Wisata}

Atraksi wisata biasanya berwujud peristiwa, kejadian, baik yang terjadi secara periodik, ataupun sekali saja, baik yang bersifat tradisional ataupun yang telah dilembagakan dalam kehidupan masyarakat modern yang kesemuanya itu mempunyai daya tarik yang positif kepada wisatawan yang mengunjungi, menyaksikan dan menikmati sehingga memberikan kepuasan yang maksimal bagi motif-motif para wisatawan yang telah tergerak untuk mengunjunginya (Damardjati 2003).

\subsubsection{Tinjauan K3 Trampoline}

American Academy of Orthopedic Surgeons (AAOS) tahun 2005 menerapkan strandar panduan penggunaan trampoline sebagai berikut, dalam pemakaian wahana trampoline harus ada pengawasan dari orang dewasa atau trainer yang memiliki pengetahuan mengenai trampoline dan tatacara pengobatan apabila terjadinya kecelakaan pada pemakai wahana, memberi pembekalan kepada trainer yang akan dipekerjakan diwahana trampoline, tujuannya agar trainer tidak salah memberikan instruksi kepada pemakai wahana trampoline, kaji tingkat keterampilan, berikan instruksi lompatan dasar, dan pastikan semua pengguna mengerti dan ikuti pedoman keselamatan trampoline,p emberian instruksi atau pemahaman kepada pemakai wahana, seperti tatacara melompat diatas trampoline, memakai kaus kaki khusus untuk bermain wahana trampoline, tujuannya agar ketika melompat diatas net trampoline pengguna tidak terpeleset dan dapat melompat secara sempurna, pemerikasaan kondisi wahana trampoline secara berkala, seperti pemeriksaan pada jaring - jaring trampoline, pegas (spring), busa peredam benturan, dan alat keselamatan lainnya.

\section{Metode Penelitian}

Penelitian ini berlokasi di Bounce Bali Kawasan Finns Recreation Club Jl. Raya Pantai Berawa no.8, Tibubeneng, Kuta Utara, Kabupaten Badung. Ruang lingkup pada penelitian ini meliputi aktifitas yang dilakukan oleh pengujung dan karyawan yang perlu menerapkan prosedur Keselamatan dan Kesehatan Kerja, dan prosedur Keselamatan dan Kesehatan Kerja yang di terapkan oleh perusahaan.

Jenis data dalam penelitian ini menggunakan data kualitatif (Moleong, 2012) dan data kuantitatif (AriKunto,2006). Sumber data menggunakan data primer dan data sekunder (Moleong,2005). Teknik pengumpulan data menggunakan observasi (Ari Kunto 2006, wawancara (Setyadin 2005), dokumentasi. Teknik penentuan informan menggunakan purposive sampling (Sugiono 2012). Teknik analisis data memakai tenik analisis data deskriptif kualitatif (Sugiono,2009). 


\section{HASIL DAN PEMBAHASAN}

\subsection{Aktivitas Bermain Trampoline}

\subsubsection{Tahap Pemanasan}

Ketika bermain trampoline di trampoline center wisatawan dituntut terlebih dahulu harus melakukan pemanasan dan peregangan agar otot tubuh tidak kaku pada saat melompat diatas trampoline. Tanpa pemanasan dapat terjadi cedera, walaupun ringan dapat menyebabkan pergerakan sendi yang ada pada tubuh dapat terganggu, dan bila terjadi cedera yang berat akan menyebabkan rusaknya syaraf yang ada pada tubuh. Pemanasan juga bertujuan untuk memperbaiki fleksibilitas pada sendi yang ada dalam tubuh.

Sehingga resiko terjadi kecelakaan yang dapat mengakibatkan wisatawan tersebut cedera dapat dihindari, karena dari efek pantulan yang diciptakan oleh trampoline ini lebih besar dari trampoline yang ada untuk dirumah. Maka dalam hal ini Bounce Bali memberikan panduan pemanasan dan peregangan sebelum melakukan aktivitas bermain trampoline di trampoline center berupa, peregangan pada bagian kepala dan bahu, peregangan pada bagian punggung dan pinggang, peregangan pada kaki, peregangan pada tubuh bagian bawah, peregangan pada pergelangan tangan, perenganga pada dada, pundak dan jari.

\subsubsection{Tahap Pengenalan Alat}

Trampoline merupakan salah satu olahraga gymnastic atau olahraga atletis yang membutuhkan kelenturan anggota tubuh. Bonunce bali menggunakan media trampoline untuk rekreasi, berbeda dengan jenis trampoline untuk kompetisi olahraga atletis. Berikut 2 jenis tipe trampoline yang digunakan di daya tarik wisata Bounce Bali yatu trampoline Jenis 1 dengan bahan dasar net, dan trampoline Jenis 2 dengan bahan dasar net khusus yang memeiliki pantulan yang lebih besar dengan bantuan spring khusus.

\subsection{Penerapan K3 Bounce Bali}

4.3.1 Faktor - Faktor Terjadinya Kecelakaan

Bentuk kecelakaan yang terjadi pada aktifitas wisata biasanya disebabkan oleh 2 faktor, yaitu faktor intenal (manusia) dan faktor eksternal (lingkungan sekitar). Berikut faktor penyebab terjadinya kecelakaan peertam Faktor Internal (
Manusia ) Faktor Fisik,, hal ini berkaitan dengan kondisi dari tubuh wisatawan yang akan bermain trampoline. Apabila wisatawan memiliki cacat pada tubuh seperti kekurangan anggota badan, maka wisatawan tersebut memiliki peluang besar akan terjadinya kecelakaan. Akan tetapi bagi wisatawan yang memiliki cacat fisik masih diperbolehkan bermain trampoline, namun tidak dianjutkan melakukan trik yang membahayakan diri wisatawan tersebut.

Faktor Penyakit, Wisatawan yang memiliki penyakit yang memerlukan perawatan khusus dianjurkan tidak bermain trampoline dengan melakukan trik - trik yang ekstrim. Penyakit yang mungkin bisa kambuh pada saat bermain trampoline seperti epilepsi, asma, penyakit jantung. Karena kondisi tubuh yang rentan akan kambuhnya penyakit tersebut. Selain itu apabila wisatawan yang sedang dalam kondisi rawat jalan, misalnya dalam kondisi retak pada tulang kaki, tidak diperbolehkan dalam permainan trampoline.

Penggunaan Alkohol dan Obat - Obatan Terlarang, dalam kondisi ini wisatawan dianjurkan tidak bermain trampoline, karena kondisi fisik yang tidak dalam kondisi normal. Sehingga kemungkinan kecelakaan terjadi akan sangat besar. Selain itu apabila wisatawan dibawah pengaruh alkohol koordinasi dari organ alat gerak pada tubuh tidak berfungsi secara normal, ketika melakukan lompatan di atas trampoline wisatawan tersebut bisa terbentur pada tempat yang keras.

Tidak Menggunakan Kaus Kaki Khusus Bermain Trampoline, dalam bermain trampoline wisatawan dianjurkan menggunakan kaus kaki khusus untuk bermain trampoline. Hal ini bertujuan agar wisatawan dapat melompat dengan sempurna. Apa bila hanya menggunakan kaus kaki biasa dampak yang akan ditimbulkan seperti terpeleset, dan sulitnya menjaga keseimbangan.

Penggunaan kaus kaki khusus trampoline bertujuan untuk meminimalisir dampak tersebut, karena bahan kaus kaki khusus trampoline ini berbeda dengan kaus kaki biasa. Pada bagian bawah kaus kaki khusus trampoline terdapat bantalan karet yang berguna untuk menahan daya gesek pada 
kaki,sehingga wisatawan pada saat melompat diaatas trampoline tidak akan terpeleset. Namun jika wisatawan tidak menggunakan kaus kaki sama sekali akan menyebabkan luka pada kaki, karena bentuk trampoline yang seperti jaring net.

Faktor Eksternal (Lingkungan Sekitar) Faktor lingkungan dalam aktivitas bermain trampoline dilihat dari kondisi trampoline yang digunakan untuk bermain. Kondisi trampoline yang sudah kurang aman untuk digunakan akan mengakibatkan terjadinya kecelakaan pada wisatawan saat bermain trampoline. Hal tersebut dapat dilihat dari kondisi net pada trampoline, apabila net tersebut memiliki lobang besar pada permukaannya maka akan beresiko apabila tetap digunakan. Selain itu spring penahan trampoline apabila sudah ada yang hilang makan juga dapat menimbulkan kecelakaan, karena sewaktu -waktu spring yang lain bisa lepas.

\subsubsection{Penerapan Keselamatan dan Kesehatan Kerja di Bounce Bali}

Penerapkan K3 yang dilakukan oleh Bounce Bali kepada wisatawan, pihak Bounce Bali memberlakukan beberapa peraturan kepada wisatawan sebelum bermain trampoline. Dimana persyaratan tersebut bertujuan untuk keselamatan wisatawan tersebut saat bermain trampoline. Berikut peraturan yang diberikan oleh Bounce Bali. Melakukan Pemanasan dan Peregangan, melakukan olahraga atau gerakan yang akan membebani tubuh maka harus melakukan pemanasan dan persegangan terlebih dahulu. Tujuan dari pemanasan dan peregangan agar ketika bermain trampoline wisatawan tidak mengalami kram dan cidera otot lain yang disebabkan oleh tidak pemanasan dan peregangan. Bounce Bali menekankan kepada setiap wisatawan yang ingin bermain trampoline harus melakukan pemanasan terlebih dahulu.

Tidak Menggunakan Pakaian Ketat, saat bermain trampoline tidak dianjurkan menggunakan pakaian yang ketat. Pakaian yang digunakan saat bermain trampoline adalah pakaian yang tidak menghalangi pergerakan, yang tujuannya agar wisatawan dapat bergerak leluasa ketika melompat diatas trampoline. Tidak Melompat di
Pinggir Trampoline, wisatawan tidak diperbolehkan melompat dipinggir trampoline karena pantulan yang dihasilkan lebih sedikit dan susah untuk dikontrol. Sehingga bisa menyebakan hilangnya keseimbangan pada wisatawan.

Selain itu pada pinggiran trampoline juga banyak terdapat besi dan spring, apabila wisatawan jatuh ditempat tersebut dapat menyebabkan luka. Dilarang Melakukan Trik Berbahaya, bagi wisatwatan yang pertama kali mencoba trampoline, dilarang melakukan trik berbahaya seperti salto dan gerakan akrobatik. Apabila wisatawan yang sudah mahir melakukan gerakan tersebut disarankan melakukannya ditrampoline yang ada busa pelindung, sehingga mengurangi resiko terjadinya cedera.

Tidak Menggunakan Perhiasan, sebelum bermain trampoline wisatawan harus menanggalkan semua perhiasan yang menggagu pada saat bermain trampoline. Apabila terjadi kehilangan bukan tanggung jawab dari Bounce Bali. Dilarang Melakukan Benturan Fisik, pada saat melompat diatas trampoline wisatawan dilarang melakukan benturan fisik. Karena akan mengakibatkan salah posisi ketika mendarat diatas trampoline, sehingga dapat mengakibatkan patah tulang leher hingga resiko kematian. Dilarang Duduk dan Tidur diatas Trampoline, aturan ini bertujuan agar tidak mengganggu kenyamanan wisatawan lain pada saat bermain trampoline. Apabila wisatawan ingin beristirahat, istirahatlah luar wahana trampoline yang sudah disediakan oleh Boounce Bali. Memperthatikan Aturan Mengenai Ketinggian, Badan pada wahana trampoline jenis 2 Bounce Bali menetapkan aturan tinggi badan minimal wisatawan untuk bermain trampoline ini $120 \mathrm{~cm}$. Karena lompatan yang dihasilkan trampoline ini 3 kali lipat lebih besar dari jenis trampoline yang pertama. Pemberian Jaminan Keselamatan dan Kesehatan . Setiap wisatawan yang menggunakan trampoline di daya tarik wisata Bounce Bali akan di berikan jaminan keselamatan dan kesehatan berupa Asuransi. 


\subsubsection{Penerapan K3 pada Karyawan}

Bounce Bali menetapkan peraturan K3 untuk karyawan berupa, pihak Bounce Bali melakukan seleksi pada karyawan yang bertujuan untuk mengecek apakah karyawan tersebut memiliki penyakit fisik dan cacat mental. Para karyawan diberikan pelatihan setiap 6 bulan sekali menganai prosedur K3, pelatihan tersebut dilakukan oleh Bounce Bali yang bekerja sama dengan Rumah Sakit BIMC.

Bounce Bali memberikan jaminan Asuransi Kesehatan kepada wisatawan berupa BPJS, dan MHC ( Mandiri Health Care ). Setiap karyawan yang ada di Bounce Bali juga dibekali pelatihan pertolongan pertama pada kecelakaan, seperti prosedur $C P R$ yaitu tindakan pertolongan pertama pada orang yang mengalami henti napas karena sebabsebab tertentu.

\subsubsection{Pencegahan dan Penanggulangan Terjadinya Kecelakaan}

Adapun pencegahan yang dilakukan agar wisatawan merasa aman pada saat bermain trampoline pihak perusahaan tentunya sudah memiliki tindakan pencegahan apa bila terjadinya kecelakaan. Langkah kedua dengan melakukan pengawasan terhadap wisatawan pada saat bermain trampoline. Tujuannya agar apabila terjadi kecelakaan staff dari Bounce Bali bisa langsung memberikan pertolongan kepada wisatwaan. Menempatkan wisatawan wisatawan sesuai kriteria kemampuan. Maksudnya apabila ada wisatawan yang memliki tinggi badan kurang dari $120 \mathrm{~cm}$, staff Bounce Bali menindak dengan menyuruh wisatawan tersebut bermain di trampoline tipe 1 dan melakukan pengecekan berkala pada wahana trampoline.langkah ketiga, penanggulangan Kecelakan, untuk mengatasi resiko yang ditimbulkan saat bermain trampoline pihak Bounce Bali sudah menetapkan standar prosedur keselamatan dan keamanan kerja . Hal ini menjadikan pihak Bounce Bali sudah mempunyai First aid room sebagai tempat untuk menangani apabila terjadi kecelakaan dan bekerja sama dengan Rumah Sakit BIMC.

\section{PENUTUP}

\subsection{Simpulan}

Aktivitas bermain trampoline di Bounce Bali sudah terbilang aman karena pihak sudah ada penetapan standar aturan permainan yang dibuat oleh Bounce Bali. Aturan yang ditetapkan tersebut sama dengan aturan strandart pada trampoline center lainnya.Penerapan K3 yang dilakukan oleh Bounce Bali sudah terbilang baik karena didukung oleh karyawan yang sudah memiliki pengalaman dibidang K3 melalui pelatihan yang dilakukan oleh Bounce Bali Pemberian jaminan Asuransi kepada wisatawan dan karyawan. Asuransi yang diberikan oleh Bounce Bali kepada wisatawan yaitu Zurich Insurance dan kepada karyawan berupa BPJS dan MHC (Mandiri Health Care). Penyediaan fasilitas penanggulangan kecelakaan yang baik. Pihak Bounce Bali menyediakan ruangan khusus untuk penanganan pertama kecelakaan yaitu dengan adanya ruangan First Aids Room.

\subsection{Saran}

Meningkatkan pengawasan oleh karyawan kepada wisatawan pada saat wisatawan bermain trampoline. Dengan demikian apabila ada wisatawan yang mengalami kecelakaan dapat langsung diatasi. Penyediaan transportasi khusus untuk wisatawan dan karyawan apabila terjadi kecelakaan yang berat.

\section{Daftar Pustaka}

Arikunto, Suharsimi (2006). Prosedur Penelitian Suatu Pendekatan Praktek, Cetakan Ketigabelas. Jakarta: PT. Rineka Cipta

AAOS, (2005). Trampoline Safety, Unite States of America : American Assosiation of Orthopaedic Surgeon.

Damardjati, (2003). Istilah-Istilah Dunia Pariwisata, Jakarta: Pradnya Paramitha

Simon, Julius (2016). Penerapan Keselamatan dan Kesehatan Kerja Pada Aktifitas Berenang Bersama Ikan Hiu. (Jurnal

Kusuma, Satwika Wiguna. (2016). PENERAPAN KESELAMATAN DAN KESEHATAN KERJA BALAWISATA DI PANTAI KUTA. (Jurnal)

Mahadewi , (2012). PARIWISATA DAN PERHOTELAN. (Jurnal)

Mangkunegara, A.A. (2001). Manajemen Sumber Daya Manusia Perusahaan. Bandung: PT Remaja Rosda Karya .

Negri, M. L. (2016). Daftar Wisatawan Nusantara. Indonesia : Kemenlu.

RoSP, (2007) Trampoline Safety,Birmingham : The Royal Society oh the Prevention of Accident.

Setyadin, (2005). "Metode Penelitian Kualitatif: Teori dan Praktik". Jakarta: BumiAkasra. 
Sugiyono, (2012). Memahami Penelitian Kualitatif. Bandung: Alfabeta.

Sugiyono, (2014). Metode Penelitian Kuantitatif Kualitatif dan R\&D. Bandung: Alfabeta.

Sugeng, (2005). Manajemen Sumber Daya Manusia Perusahaan. Jakarta : PT. Gramedia Pustaka Utama.

Suharsimi, Arikunto. (2010). Prosedur Penelitian Suatu Pendekatan Praktik. Jakarta: PT. Rineka Cipta.

Sunaryo , Bambang, (2013). Kebijakan Pembangunan Destinasi Pariwisata : Konsep dan aplikasinya di Indonesia, Yogyakarta; Gava Media.
Zainal, V. R., Ramly, M., Mutis, T., \& Arafah, W. (2014) Manajemen Sumber Daya Manusia Untuk Perusahan Dari Teori Ke Praktik. Rajawali Pers .

Sumber Lainnya :

http://pediatrics.aappublications.org/content/130/4/774.f ull. Diakses pada tanggal 18 April 2017.

http://www.mrtrampoline.com.au/in-ground-trampolines/. Diakses pada tanggal 20 April 2017.

http://www.trampolinesforyou.com/. Diakses pada tanggal 3 Mei 2017.

http://bouncebali.com/. Diakases pada tanggal 3 Mei 2017. 